\title{
ON THE QUESTION OF PREDICTING THE SERVICE LIFE OF LATTICE STEEL STRUCTURAL ELEMENTS
}

\author{
Oleg Vladimirovich Emelianov* \\ Magnitogorsk State Technical University, Magnitogorsk, Russian Federation \\ Alexander Nikolaevich Shuvalov \\ Moscow State University of Civil Engineering, Moscow, Russian Federation \\ Milan Prokic \\ LLC Velesstroy, Moscow, Russian Federation
}

Present paper deals with the evaluation of fatigue strength at crack initiation stage in the double angle elements of lattice steel structures. The current construction norms for steel structures do not include check for fatigue strength at crack initiation stage, and the calculation of elements endurance limit does not account actual stress-strain state in stress concentration zones, material deformation characteristics in these areas, and strength properties of steel. Experimental study of the stress-strain state kinetics in the areas of gusset plate breakage of double angle welded joints was carried out by strain gauge method. Results were obtained regarding the stress state stabilization under cyclic loading and stress intensity factor. During cyclic tests, maximum load level varied depending on the yield stress. The formation of fatigue cracks was detected in the zone of gusset plate breakage.The curve at fatigue cracks initiation stage, by deformational fracture criteria at "stiff" loading, was described by the equations presented in the "Standards of strength calculation of equipment and pipelines of nuclear power plants". Calculation analysis of results for number of cycles before fatigue crack initiation has been made and good agreement with test results has been obtained.

Key words: Steel lattice structures, Fatigue crack, Fatigue strength, Elastoplastic deformation of the material, Deformation fracture criterion, Cyclic loading, Stress intensity factor

\section{INTRODUCTION}

Welded steel structures and constructions (reservoirs, gas tanks, pipelines, pressure vessels, masts, towers, crane beams, load-bearing structures of industrial buildings, etc.) have found wide application in various branches of industry. Failures in operation of structures usually occur as a result of the bearing capacity loss or failure of the individual construction elements [01]. Accidents are often accompanied by, considerable material and environmental damage, and sometimes, even human losses. For steel lattice structures, which operate under cyclic loads (truss structures of industrial buildings with underslung cranes, bunker structures and unloading racks, towers, masts, power lines supports, etc.), the presence of structural stress concentration, residual welding stresses and initial technological welding defects is characteristic. For design of struc- tural elements considering the operating conditions of such structures, additional analysis of fatigue strength must be performed [06,07]. In current construction norms (SP 16.13330.2011) calculation of the fatigue is provided only when the number of loading cycles $\geq 105$ and it is performed by comparing the maximum normal stresses with calculated fatigue strength, which is given for several types of welded joints. In construction norms, influence of defects on the strength and lifetime of the structure is ignored. It is assumed that during the lifetime of structure, calculated sections must be free from cracks, including fatigue cracks. However, operating experience of building structures under cyclic load shows that the elastoplastic material deformation is accompanied with a damage accumulation and leads to the fatigue crack initiation in stress concentration zones [10, 11]. 


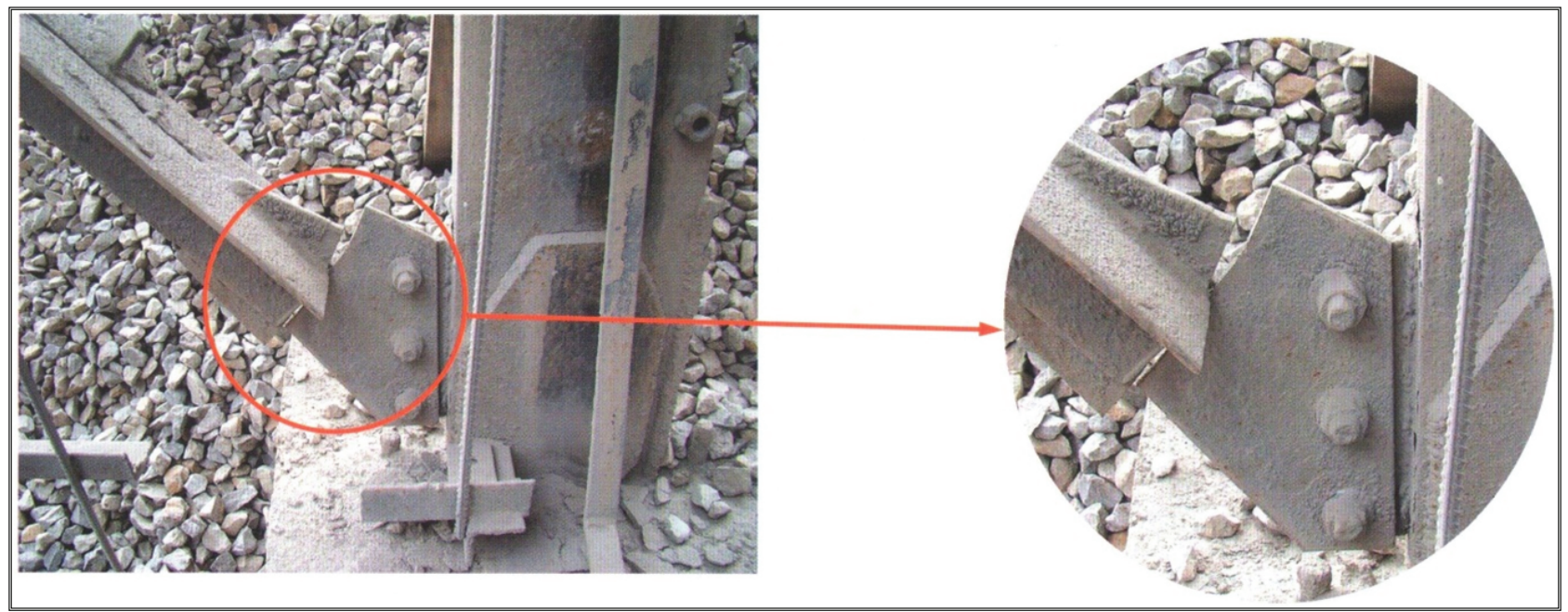

Figure 1: Welded double angle connection fatigue failure

To describe the process of fatigue cracks initiation, a number of models have been proposed, based on the presence of local plastic deformations. Present paper studies the effect of cyclic influences in which the stress magnitude in structure sections is constantly changing with time.

\section{MATERIAL AND METHODS OF TESTING}

Welded elements for the tests (Figure 2) were made form low alloy steel 10G2S1 (\lrcorner L70×6) and steel $S 390(\lrcorner L 80 \times 8)$ obtained by heat treatment of VSt3sp (RSt37-2) steel during the rolling process. Mechanical properties of steels determined by the test results of standard samples are shown in Table 1.

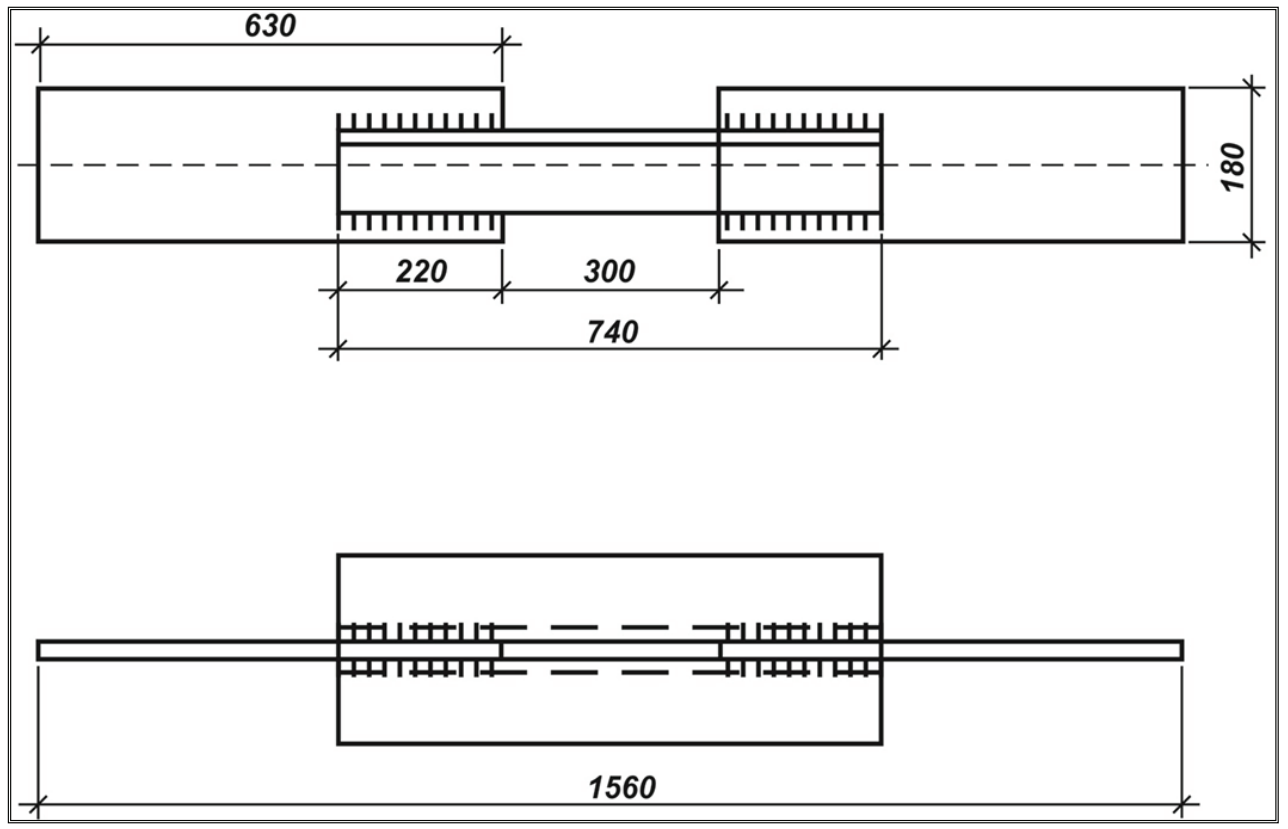

Figure 2: Welded T-section connection out of double angles

Table 1: Mechanical properties of steels

\begin{tabular}{|c||c||c||c||c||c||}
\hline \multirow{2}{*}{ Steel grade } & \multicolumn{4}{|c||}{ Steel properties } \\
\cline { 2 - 6 } & $\sigma_{\mathrm{y}, \mathrm{MPa}}$ & $\sigma_{\mathrm{B}, \mathrm{MPa}}$ & $\Psi, \%$ & Sk, MPa & $\mathrm{E}, \mathrm{MPa}$ \\
\hline \hline $10 \mathrm{G} 2 \mathrm{~S} 1$ & 350 & 530 & 57,4 & 956 & $2 \times 10^{5}$ \\
\hline \hline $\mathrm{S} 390$ & 390 & 542 & 63 & 1020 & $2 \times 10^{5}$ \\
\hline
\end{tabular}


The study of fatigue cracks initiation conditions in welded joints with double angles was carried out by cyclic tension loading in the zone of gusset plate breakage with preset load level ("soft" loading"). Cyclic loading of the connection was carried out at various load levels up to the joint failure. In the process of loading the moment of fatigue cracks initiation was recorded. Tests were carried out on a hydraulic pulsator system GRM-1 with loading frequency 7.25 $\mathrm{Hz}$ and cycle asymmetry coefficient $\mathrm{R}=0,2$. Maximum rated load levels were $\sigma^{-} n=\sigma \_n / \sigma_{-}$ $T=0,175 ; 0,231 ; 0,351 ; 0,526$ for elements of 10G2S1 steel and $\sigma_{-} \mathrm{n}=\sigma \_\mathrm{n} / \sigma_{-} \mathrm{T}=0,208 ; 0,229$; 0,$261 ; 0,313 ; 0,417$ for elements of S390 steel.

Since the conditions of fatigue cracks initiation were investigated in joints which do not contain defects form processing, testing was preceded by an external inspection of welded joints. After the completion of tests, fractures and internal technological defects were inspected.

\section{TEST RESULTS AND THEIR DISCUSSION}

Main cracks with $2 \div 4 \mathrm{~mm}$ length, were detected on the angle heel edge in the gusset plate breakage area. At this length, the number of sample loading cycles was determined, corresponding to that crack. The share of the relative service life at crack initiation stage was $0,127 \div 0,7$ (average $30 \%$ ) of total fatigue service life of double angle welded joints (Table 2). It should be noted that the share of relative service life of welded joints from S390 steel is lower than in joints from 10G2S1 steel. This takes place at the crack initiation stage with the same level of nominal cyclic stresses. Figure 3 shows a comparison of the fatigue strength results obtained by calculation according to the existing construction norms, with the results of experimental fatigue tests of welded standard elements out of double angles.

Table 2: Number of cycles before fatigue crack initiation and joint failure

\begin{tabular}{|c|c|c|c|c|}
\hline \multirow{2}{*}{$\begin{array}{l}\frac{0}{0} \\
\frac{\pi}{0} \\
\overline{0} \\
\text { के }\end{array}$} & \multirow{2}{*}{$\begin{array}{l}\text { Maximum } \\
\text { level of nomi- } \\
\text { nal stresses, } \\
\sigma_{n, \mathrm{MPa}}\end{array}$} & \multicolumn{2}{|c|}{$\mathrm{N}_{\mathrm{f}}^{\text {exp }}$ Number of cycles } & \multirow{2}{*}{$\begin{array}{rl} & \frac{N_{\mathrm{ci}}^{\exp }}{N_{\mathrm{f}}^{\exp }} \\
* & 100 \%\end{array}$} \\
\hline & & $\begin{array}{l}\text { Before crack initiation } \\
\mathrm{I}=2 \div 4 \mathrm{~mm} \text { length }\end{array}$ & $\mathrm{N}_{\mathrm{f}}^{e x x}$ before joint failure & \\
\hline \multirow{6}{*}{$\begin{array}{l}\bar{N} \\
\text { ঠै } \\
\text { ○ }\end{array}$} & 0,526 & 18300 & 26100 & 70,11 \\
\hline & 0,351 & 117900 & 467600 & 25,21 \\
\hline & 0,351 & 105700 & 459000 & 23,03 \\
\hline & 0,231 & 335000 & 722100 & 46,39 \\
\hline & 0,231 & 308900 & 624200 & 49,49 \\
\hline & 0,175 & 722970 & 2033625 & 35,55 \\
\hline \multirow{8}{*}{ 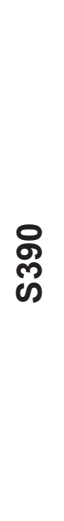 } & 0,417 & 56100 & 202300 & 27,73 \\
\hline & 0,417 & 18300 & 180100 & 10,16 \\
\hline & 0,313 & 74800 & 590700 & 12,66 \\
\hline & 0,313 & 86400 & 549000 & 15,74 \\
\hline & 0,261 & 217100 & 705000 & 30,79 \\
\hline & 0,23 & 312000 & 1200100 & 26,00 \\
\hline & 0,23 & 332900 & 1281100 & 25,99 \\
\hline & 0,208 & 459600 & 2098900 & 21,90 \\
\hline
\end{tabular}




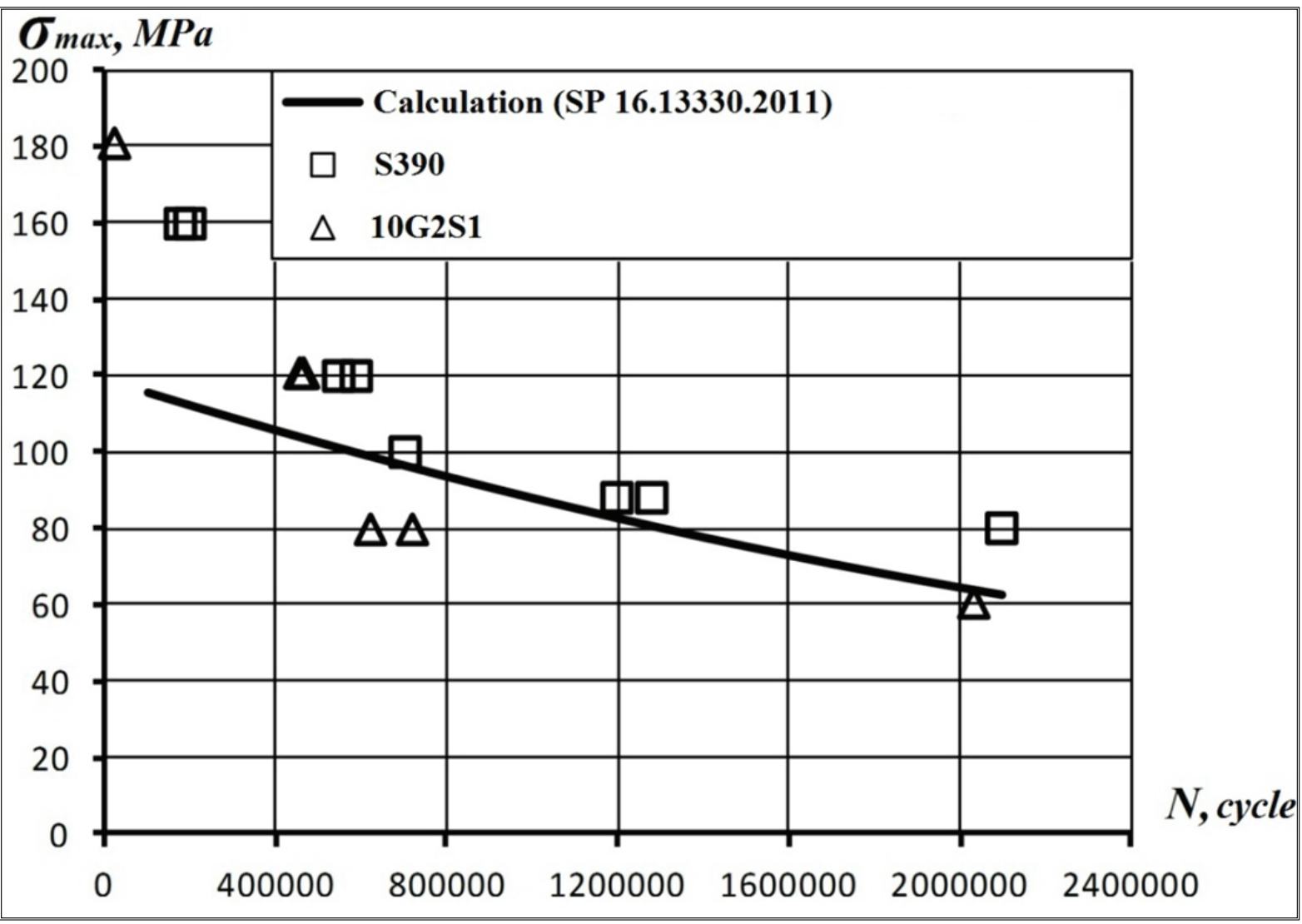

Figure 3: Calculated fatigue strength curve and results of fatigue tests for structural elements form 10G2S1 u S390 steel

It can be seen that the calculation with the use of current construction norms (SP 16.13330.2011) overestimates values of fatigue strength for 10G2S1 steel, and underestimates fatigue strength for the S390 steel [08]. This is caused by fact that in these construction norms (for the elements of groups 3-8) calculated fatigue resistance is independent of strength and cyclic properties of the steel, the design parameters of welded joint (width of the angles, length and throat of welded joints) [02].

It is quite difficult to detect a fatigue crack on time. Therefore, to ensure the safety and calculated service life of welded steel structures during the design calculations must be performed not only on the assumption of cracks absence, but also their emergence and development, predicting the limit state of crosssections, in which the cracks are developed. Since fatigue cracks are formed in areas with high stress concentration, the actual strain and stress distribution in these areas is important for predicting the number of cycles to crack initiation. Features of such calculations are the mechanical characteristics of metal in various areas of joint and presence of residual welding stresses. Study of welded joints strain state, as well as cyclic deformation diagrams for joints with different classes of construction steels was conducted by Larionov V.V. [04]. Currently, construction norms for structures calculation are developed, in which fatigue crack initiation is considered to be a limit state of structure. These norms are based on deformation failure criterions, which are taking into account the kinetics of local elastoplastic deformations at unitary and cyclic loading. For calculating the maximum local strains and stresses, most widely used are formula of Makhutov N.A. [5], allowing to determine stress intensity factors $\mathrm{K}_{\mathrm{\sigma i}}$ and deformation factors $\mathrm{K} \varepsilon \mathrm{i}$ in elastoplastic area by the values of stress intensity factor in elastic deformation area $\alpha_{\sigma}$. The dependence of elastic stress intensity factors on the design parameters of typical welded elements of double angles are given in paper [02]. However, these expressions do not take into account specific material resistance to elastoplastic deformation. N.A. Makhutov proposed dependences for account 
ing material properties, which allow estimating the material resistance in elastoplastic deformation area under static and cyclic loading [05]. In present paper, an experimental study of the stress-strain state kinetics under elastoplastic material deformation in areas of gusset plate breakage of double angle welded joints (Figure 2) using foil strain gauges with $1.0 \mathrm{~mm}$
It was found that the stabilization of stressstrain state occurs after 5-10 loading cycles and $\alpha_{\sigma}=K \varepsilon j^{(k)}$ in the investigated relative range of cyclic loads application $\sigma_{n}=\sigma_{n} / \sigma_{y}=0,16 \div 0,62$ (Figure 4). Material in the stress concentration zones was working in "stiff" loading conditions, with constant amplitude of deformations $E_{a}$. base.

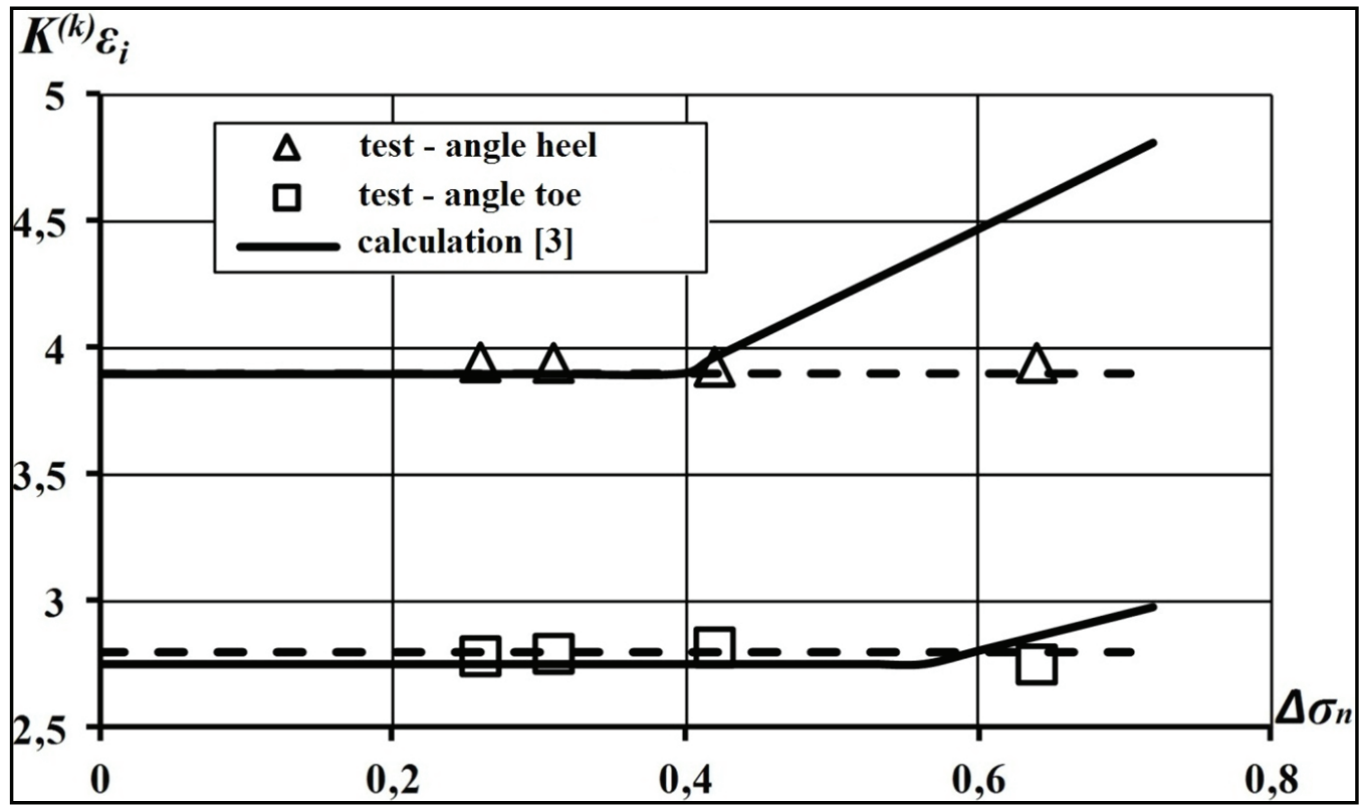

Figure 4: Dependence of strain concentration factors in stabilized range $K \varepsilon i^{(k)}$ on the cyclic loading level in the gusset plate breakage area

A suggested fatigue curve equations at crack initiation stage for steels with ratio $\sigma_{\top} / \sigma_{\mathrm{B}} \leq 0,7$ and the number of loading cycles $\leq 106$ by failure criterion at "stiff" loading are:

By "Standards of strength calculation of equipment and pipelines of nuclear power plants" [09]:

$$
\left[\sigma_{a F}\right] \varphi_{s}=\frac{E^{m} e_{c}^{m}}{n_{\sigma}\left(4\left[N_{0}\right]\right)^{m}}+\frac{R_{-1}^{m}}{n_{\sigma}\left(1+\frac{R_{-1}^{m}}{R_{m}^{m}} \frac{1+r}{1-r}\right)}(1)
$$

where $n_{\sigma}-$ safety factor for stresses; $\left[\sigma_{a F}\right]-$ the amplitude of conventional elastic stresses taking into account stress intensity factor, which can be determined from $\left[\sigma_{a F}\right]=\left(\sigma_{H}{ }^{\max }-\sigma_{H}{ }^{\min }\right) \alpha_{\sigma} / 2 ; \varphi_{S}$ -a coefficient that depends on the welding type, welded materials and post weld heat treatment $\left(\varphi_{s} \leq 1\right) ; R_{c}{ }^{\top}, E^{\top}, \Psi^{\top}, \sigma_{m}{ }^{\top}, R_{-1}{ }^{\top}-$ material properties at a temperature $\mathrm{T}^{\circ} \mathrm{C} ; \mathrm{e}^{\top}{ }^{\top}$ - plasticity characteristic: $\mathrm{e}_{c}{ }^{\top}=0,005 \psi^{\top}-\left(\left(\sigma_{F}\right)_{\max }-\sigma_{m}{ }^{\top}\right) /\left(2 E^{\top}\right)$ at $\left(\sigma_{F}\right) \max >\sigma_{m}{ }^{\top}$ and $\mathrm{ec}^{\top}=0,005 \psi^{\top}$ at $\left(\sigma_{\mathrm{F}}\right)_{\max }<\sigma_{\mathrm{m}}^{\top} ; \mathrm{m}$ - exponent: $\mathrm{m}=0,5 ; \mathrm{Rc}^{\top}$ - strength characteristic: $\mathrm{R}_{\mathrm{c}}{ }^{\top}=\mathrm{R}_{\mathrm{m}}{ }^{\top}$ $\left(1+1,4 \Psi^{\top}\right) ;\left(\sigma_{F}\right)_{\max }-$ maximum conditional elastic stress cycle with account for conditional elastic stress intensity factor; $R_{-1}{ }^{\top}=0,4 R_{m}{ }^{\top} ; r$ - asymmetry coefficient of stress cycle $r=\left(\sigma_{m}{ }^{\top}-2\left[\sigma_{a F}\right]\right) /\left(\sigma_{m}{ }^{\top}\right)$;

In case when local deformations in stress concentration zones from service loads in strained state are determined experimentally and by solving the elastoplastic problem. Then, the number of cycles before crack initiation is calculated by equation [2]

$\varepsilon_{a}=\frac{\ln \frac{100}{100-\psi^{t}}}{\left(4\left[N_{0}\right]\right)^{m} p+\frac{1-r^{*}}{1-r^{*}}}+\frac{\sigma_{-1}^{t} / E^{t}}{1+\frac{\sigma_{-1}^{t}}{\sigma_{6}^{t}} \frac{1+r}{1-r}}$

where $\left.\varepsilon_{\mathrm{a}}=\left(\sigma_{H}{ }^{\max }-\sigma_{\mathrm{H}}{ }^{\min }\right) \mathrm{K} \varepsilon i^{(k)}\right) / 2 \mathrm{E} ; r^{*}=\sigma_{\text {min }} / \sigma_{\max } ; r=1-$ $\left(2 \sigma_{\mathrm{a}}{ }^{*} /\left(\sigma_{\max }{ }^{*}\right)^{\left(\mathrm{m}^{\wedge}(0)\right)} ; \mathrm{E}^{\mathrm{t}}, \psi^{\mathrm{t}}, \sigma_{\mathrm{B}}^{\mathrm{t}}, \sigma_{(-1)}{ }^{\mathrm{t}}\right.$ - material characteristics at a temperature $\mathrm{T}^{\circ} \mathrm{C}$.

As applied to welded joints, heat treated or without heat treatment, which contain residual stresses in the absence of experimental data in equation (2) instead of the fatigue limit $\sigma_{(-1)}{ }^{t}$ fatigue limit for welded joints $\sigma_{(-1 c)}=\sigma_{(-1)}\left(1-\sigma_{\sigma}\left(\sigma_{B}\right)[03]\right.$ is introduced. 
For welded joints without heat treatment in a first approximation residual stresses $\sigma 0$ are assumed equal to the yield stress of material or weld metal. In calculations, the value of relative narrowing is recommended to be taken according to the guides "Steel structures" volume $1-\psi_{\mathrm{rn}}=0,8 \psi^{\mathrm{t}}$; "Welding in mechanical engineering" volume $3-\psi_{\mathrm{m}}=(0,15 \div 0,6) \psi^{\mathrm{t}}$. Figure $5 \mathrm{a}$, b shows a comparison of curves calculated according to the equation (1) and (2) with the experimental data, within the investigat- ed range of fatigue failures. In the calculations were accepted: equation (1) $-n_{\sigma}=2, \varphi_{s}=0,75$ for 10G2S1 steel, $\varphi_{s}=0,65$ for $S 390$ steel; equation (2) - relative narrowing in the transition area $\psi_{\mathrm{rn}}=0,6 \psi^{\mathrm{t}}$. The graphs show that within the investigated range of fatigue failures, a good agreement between curves calculated by equation (2) and experimental data is obtained. Calculation by the equation (1) gives lower values of cycles before fatigue crack initiation for 10G2S1 steel.

(a)

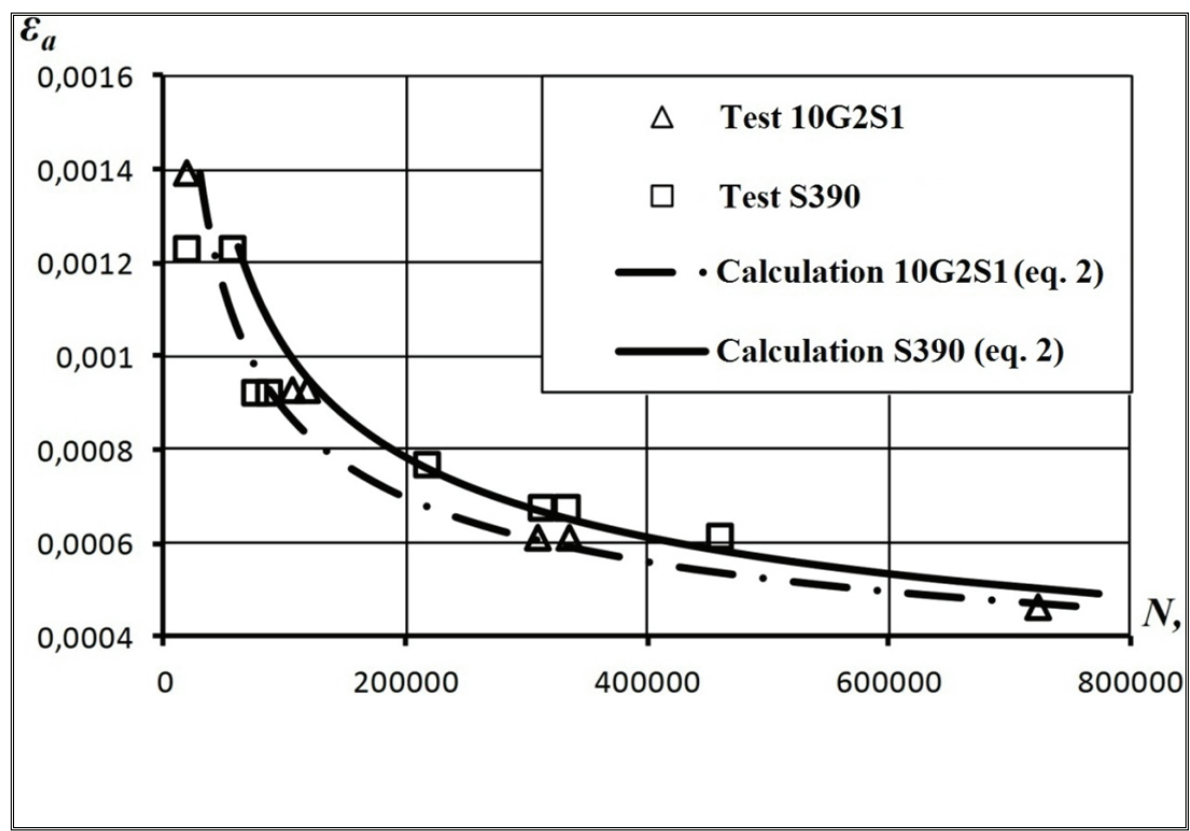

(b)

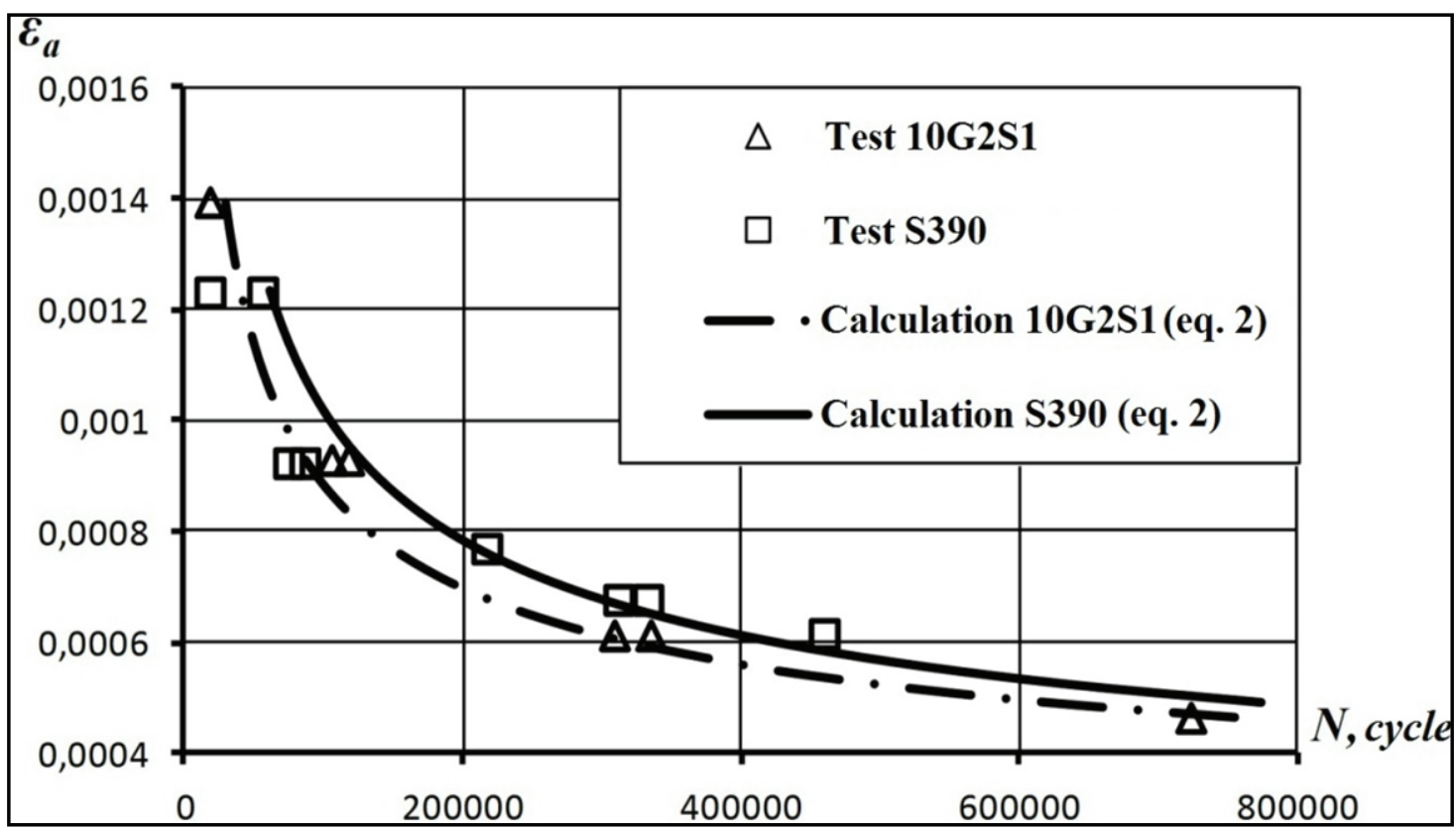

Figure 5: Comparison of calculated curves for cycles before fatigue crack initiation with the results of endurance tests of structural elements from 10G2S1 steel and S390 steel: a) by the equation (1); b) by the equation (2) 


\section{CONCLUSION}

1) According to current construction norms (SP 16.13330.2011), the calculation of lattice steel structural elements out of double angles overestimates fatigue strength for 10G2S1 steel, and underestimates fatigue strength for the $\mathbf{S 3 9 0}$ steel. This is because in these construction norms, fatigue resistance calculation does not consider strength and cyclic properties of the steel and design parameters of welded joint (width of the angles, length and throat of welded joints).

2) The share of the relative service life at crack initiation stage was on average $30 \%$ of total fatigue service life for all tested joints out of double angles.

3) The safety and calculated service life of welded steel structures depends on the presence of stress concentrations, residual welding stresses and initial technological welding defects. Therefore, design calculations of steel structures must be performed not only with the assumption of cracks absence, but also their emergence and development, predicting the limit state of cross-sections, in which the cracks are developed.

4) Comparison of experimental data with calculated number of cycles before fatigue crack initiation by the expressions (1) and (2) showed that good agreement is obtained with size of relative narrowing in the transition area $\psi \_r n=0,6 \psi^{\wedge}$ t. Calculations by equation (1) with a voltage safety factor equal $n \_\sigma=2$ give underestimated values for number of cycles before fatigue crack initiation for 10G2S1 steel.

\section{REFERENCES}

1) Emelianov O.V., Bultykov A.V., Shuvalov A.N. (2012): Influence of Design Parameters of Elements Welded of Double Angles on the Level of Stress Concentration of Connection in the Zone of a Gusset Breakage, Industrial and Civil Engineering, 12, pp. 10-12

2) Eremin K.I., Makhutov N.A., Pavlova G.A., Shishkina N.A. (2011): The register of accidents of buildings and constructions of 20012010, Magnitogorsk: Magnitogorsk publishing, $318 \mathrm{p}$.

3) Kogaev V.P., Makhutov N.A., Gusenkov A.P. (1985): Calculation of machine parts and structures for strength and durability: handbook, Moscow: Mashinostroenie, 223 p.

4) Larionov V.V., Bogdyl' P.T. (1973): Study of the state of strain in welded joints using photoelastic coatings, in connection with strength at loading cycles, Low-Cycle Fatigue in Welded Structures, Seminar Materials [in Russian], Leningrad pp. 63-67

5) Makhutov N.A. (1981): Strain fracture criteria and strength design of structural members, Moscow: Mashinostroenie, $272 \mathrm{p}$.

6) Maksimović S., Blažić M., Maksimović M. (2010): Design of constructions with respects to fatigue and fracture mechanics, Journal of Applied Engineering Science, Vol. 8, No. 4, pp. 181-188

7) Perović Z.D. (2014): Accuracy of numerical methods for assessment of fatigue crack growth in welded joints, Zavarivanje i zavarene konstrukcije, vol. 59, no. 4, pp. 151157

8) PNAE G-7-002-86. Standards of strength calculation of equipment and pipelines of nuclear power plants (1989): Moscow: Metallurgiya, $524 \mathrm{p}$.

9) SP 16.13330.2011. Steel structures. The updated edition SNiP II-23-81* (2011): Moscow: OAO «TsPP» Publ., $173 \mathrm{p}$.

10) Tetelman A.S., McEvily A.J. (1967) Fracture of structural materials, New York: John Wiley, p. 186

11) Wood W.A. (1958): Recent observations on fatigue fracture in metals. ASTM STP 237, pp. $110-121$

Paper sent to revision: 04.02.2016.

Paper ready for publication: 05.03.2017. 